\title{
Adaptation and comparative study of thermal comfort in naturally ventilated classrooms and buildings in the wet tropical zones
}

\author{
Modeste Kameni Nematchoua ${ }^{\mathrm{a}, *}$, René Tchinda ${ }^{\mathrm{b}}$, José A. Orosa ${ }^{\mathrm{c}, *}$ \\ a Environmental Energy Technologies Laboratory, University of Yaoundé I, Yaounde, Cameroon \\ ${ }^{\mathrm{b}}$ LISIE, University Institute of Technology Fotso Victor, University of Dschang, Dschang, Cameroon \\ ${ }^{c}$ Department of Energy and M. P. Escuela Técnica Superior de N. y M, University of A Coruña, Paseo de Ronda 51, 15011 A Coruña, Spain
}

\section{A R T I C L E I N F O}

\section{Article history:}

Received 15 April 2014

Received in revised form 9 September 2014

Accepted 15 September 2014

Available online 22 September 2014

\section{Keywords:}

Naturally ventilated

Wet tropical

Thermal comfort

Comparative study

Buildings

\begin{abstract}
A B S T R A C T
This paper presents the results of a study relating to thermal comfort in 28 buildings and schools, in the coastal and central areas of Cameroon. This research was conducted during the dry and rainy seasons, employing the adaptive approach, in naturally ventilated buildings, in accordance with ASHRAE 55/2004, ISO 7730 and ISO 10551 . Wind speed, air temperature, relative humidity and $\mathrm{CO}_{2}$ levels were measured, and 2650 questionnaires were distributed simultaneously. The results revealed that $76.7 \%$ of the voters in Douala found the results environmentally acceptable, as against 82.6\% in Yaoundé. On average, 74.6\% of the respondents found that these were within the comfort range, while $25.3 \%$ were neutral. When the local thermal comfort factor was analysed, it was found that the percentage of dissatisfied persons exceeded $40 \%$ in both cities, Yaoundé in particular, due to its higher average temperature.
\end{abstract}

(c) 2014 Elsevier B.V. All rights reserved.

\section{Introduction}

A comfortable and healthy environment is a prerequisite for robust human health. The concept of thermal comfort is quite complex and varies according to each subject [1]. However, although many international standards have defined the range of comfort, opinions still stand still widely divided. Comfort has been defined as the state of mind that expresses satisfaction with the environment [2]. As people spend a great percentage of their time in indoor ambiences [3], the indoor environment should be designed and operated to ensure the thermal comfort and health of its occupants. The results obtained from various studies showed that people do not wholly express their feelings regarding thermal preferences in naturally ventilated environments. The research works conducted [4-7] revealed the influence exerted by the physical, physiological and psychological feelings of peoples' preferences in a naturally ventilated environment. Different approaches were used in the studies performed over the past few years to ascertain the optimum levels of thermal comfort. This proactive approach is a development of the analytical approach initiated by Fanger [8]. It is based

\footnotetext{
* Corresponding authors at: University of Yaoundé I, Environmental Energy Technologies Laboratory, Yaounde, Cameroon. Tel.: +237 76965374; fax: +23722353866

E-mail addresses: kameni.modeste@yahoo.fr (M.K. Nematchoua), jaorosa@udc.es (J.A. Orosa).
}

on the calculation of the predicted mean vote (PMV) and predicted percentage of the dissatisfied (PPD) from six main parameters established by Macpheson [9] including, clothing and metabolic resistance, dry bulb temperature, radiant temperature, relative humidity and wind speed. Today, most researchers opt for the adaptive or proactive model. The work performed in Australia, besides those conducted in the USA, Africa and Europe [10-19] highlight the importance of the adaptive models. The results obtained varied widely, depending upon the location of the study and the climatic seasons prevalent there. In particular, air temperature is one of the elements which directly affects the thermal comfort in a room. Several studies in the literature emphasised the importance of thermal comfort on productivity in buildings, offices, classrooms and other enclosed spaces. Therefore, Hussein and Hazrin [20] headed a case study in a health clinic located in southern Malaysia. Their results showed that over $80 \%$ of the respondents voted the thermal conditions to be acceptable and, despite this, those who were neutral were not always satisfied with the thermal conditions. Furthermore, Hens [21], using two practical case studies of thermal comfort during working hours, found a PMV of zero and a PPD greater than $5 \%$, in clear disagreement with the actual standards. Consequently, new models, like local thermal comfort indices, must be analysed under such conditions.

On the other hand, in a field survey performed in Jos (Nigeria) developed by Ogbonna [22], the range of acceptable conditions in tropical classrooms has been recommended. Furthermore, in 


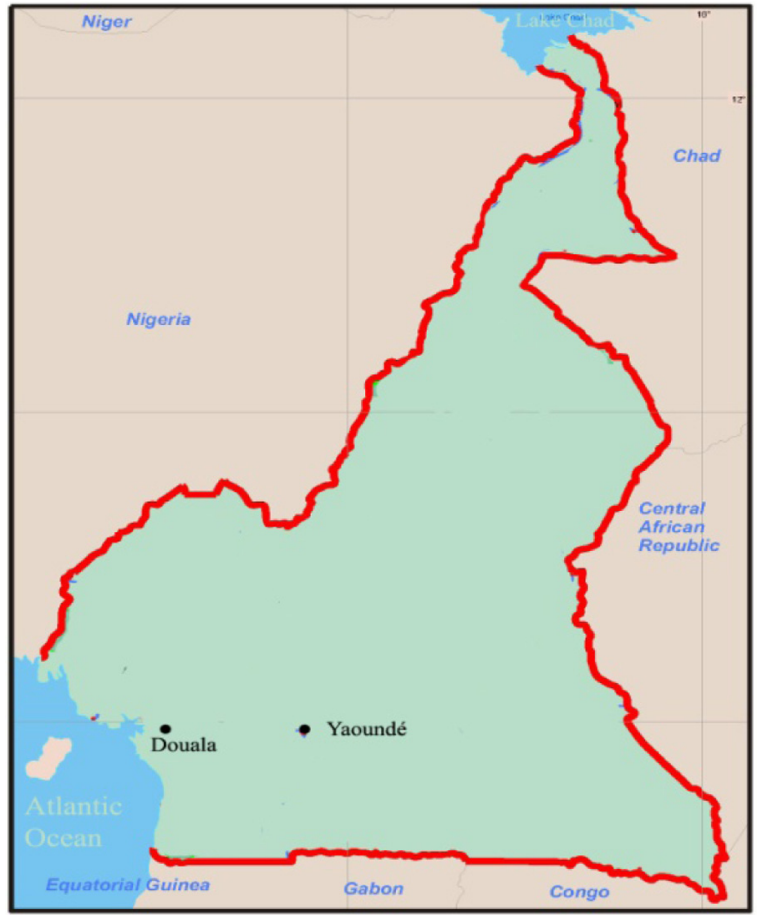

Fig. 1. Location of the city studied.

the research done by Zingano in Malawi [23] the importance of comfort-level temperature has been specified. Finally, Miyazawa [24] demonstrated that during the different sleep stages, the temperature range of thermal neutrality hovers between $19^{\circ} \mathrm{C}$ and $25^{\circ} \mathrm{C}$. This study aims to compare the results obtained from an experimental study of thermal comfort in the tropical wet and warm (e.g., Douala) and tropical wet and cold (e.g., Yaounde) regions. In the present research work, a study is presented on the thermal comfort in 28 buildings and schools in the coastal and central regions of the Cameroon, based on the adaptive approach and local thermal comfort models. The questionnaire method was employed and physical measurements were taken simultaneously to obtain the neutral thermal comfort conditions in these regions. This first study can be the key to defining new strategies to improve thermal comfort conditions and reduce the building energy consumption in these indoor ambiences.

\section{Field study}

\subsection{Cities analysed}

Douala and Yaoundé rank among the largest cities in Central Africa, as seen in Fig. 1. Douala is the economic capital of Cameroon, the main business centre and one of the major cities in the country, located on the Atlantic Ocean coast, between $4^{\circ} 03^{\prime} \mathrm{N}$ and $9^{\circ} 42^{\prime} \mathrm{E}$, covering an area of nearly $210 \mathrm{~km}^{2}$. The climate in Douala is tropical wet and hot, characterised by temperatures between $18^{\circ} \mathrm{C}$ and $34^{\circ} \mathrm{C}$, accompanied by heavy precipitation, especially during the rainy season from June to October. The air nearly always records $99 \%$ relative humidity during the rainy season and about $80 \%$ during the dry season, between October and May.

The city of Yaoundé, on the other hand, is the political capital of Cameroon, located centrally, at an altitude between $600 \mathrm{~m}$ and $800 \mathrm{~m}$ and approximately $300 \mathrm{~km}$ from the Atlantic coast. It enjoys a sub-equatorial climate (tropical wet and cold), with four seasons, including a long dry season (mid-November to late March), a short rainy season (April to mid-June), a short dry season
(mid-June to mid-August), and a long rainy season (mid-August to mid-November). The city is spread over several hills, and enjoys a relatively fresh climate, much better than that along the coast, with the maximum temperature ranging between $30^{\circ} \mathrm{C}$ and $35^{\circ} \mathrm{C}$ and a minimum temperature of $15^{\circ} \mathrm{C}$.

\subsection{Materials}

In this study, the indoor air velocity, relative humidity, $\mathrm{CO}_{2}$, temperature and surrounding light intensity were measured using the Thermo-Anemometer Model C.A1226, $\mathrm{CO}_{2}$ Monitor model CO200 and a Light Meter IM-1308, respectively. The outdoor temperature, wind speed, and relative humidity values were simultaneously collected from the National Weather Station System. The main characteristics of the measurement system employed in this work are shown in Table 1. All equipment were calibrated before each experiment to ensure reliability and accuracy in the readings recorded during the field studies.

\subsection{Methodology}

The study was conducted during the summer and winter seasons in naturally ventilated buildings, adopting the adaptive approach and using questionnaires to obtain quantitative data on the actual conditions prevailing in these habitats. To achieve this objective, two data collection methods were used, namely, a questionnaire as the subjective measurement and a physical measurement of certain parameters that influence the thermal comfort conditions in buildings. In each building, in accordance with prior research works, sampling processes were performed between two and five days per season, in each different room or office. For multistorey buildings, the offices chosen were those that supported a greater number of occupants. Table 2 shows some of the study periods. Regularly and prior to the distribution of the questionnaires, some questions were filled up regarding the occupants, such as personal data (age, sex) and micro thermal aspects (climatic control), to elicit better responses to the questionnaires.

The mean radiant temperature $\left(T_{r}\right)$ was estimated using the regression model shown in Eq. (1) as a function of the air temperature measured $\left(T_{a}\right)$ proposed by Nagano [29] under a determination factor of 0.99 .

$T_{r}=0.99 \times T_{a}-0.01, \quad R_{2}=0.99$

At the same time, the operative temperature $\left(T_{0}\right)$ was determined from the air temperature measured $\left(T_{a}\right)$ and the mean radiant temperature $\left(T_{r}\right)$, as seen in the following equation [2]:

$T_{o}=A \times T_{a}+(1-A) \times T_{r}$

where the weighting factor $(A)$ depends on air velocity $(w)$, as the following equation:

$$
\begin{aligned}
& A=0.5 \text { for } w<0.2 \mathrm{~m} / \mathrm{s} \\
& A=0.6 \text { for } 0.2<w<0.6 \mathrm{~m} / \mathrm{s} \\
& A=0.7 \text { for } 0.6<w<1 \mathrm{~m} / \mathrm{s}
\end{aligned}
$$

\subsubsection{Field measurement of the environmental parameters}

Measurements were taken every $20 \mathrm{~min}$ at a height of $1.2 \mathrm{~m}$ from the ground level in strict accordance with the prescriptions of the ASHRAE Standard 55 [2] and ISO 7730 Standard [25]. Once the devices were installed, measurements were recorded starting from 8:00 AM, to enable each unit to get adapted to the environment. The data were noted regularly until 7:00 PM. These measurements provided four of the six parameters established by Macpheson [9] including those of air velocity, relative humidity, ambient temperature and average radiant temperature. These parameters were then 
Table 1

Characteristics of the measurement system.

\begin{tabular}{|c|c|c|c|c|}
\hline & Function & Range & Resolution & Accuracy \\
\hline $\mathrm{CO}_{2}$ monitor (model & $\mathrm{CO}_{2}$ & 0-9999 ppm & $1 \mathrm{ppm}$ & $\pm(5 \% \mathrm{rdg}+50 \mathrm{ppm})$ \\
\hline \multirow[t]{4}{*}{ CO200) } & Temperature & $-10^{\circ} \mathrm{C}$ to $60^{\circ} \mathrm{C}$ & $0.1^{\circ} \mathrm{C}$ & $\pm 0.6^{\circ} \mathrm{C}$ \\
\hline & & $14^{\circ} \mathrm{F}$ to $140^{\circ} \mathrm{F}$ & $0.1^{\circ} \mathrm{C}$ & $\pm 0.9^{\circ} \mathrm{F}$ \\
\hline & Humidity & $0.1 \%$ to $99.9 \%$ & $0.1 \%$ & $\pm 3 \%(10-90 \%)$ \\
\hline & & & & $\pm 5 \%(<10 \%$ or $>90 \%)$ \\
\hline \multirow[t]{3}{*}{ Digital thermometer } & Temperature & $-20^{\circ} \mathrm{C}$ to $0^{\circ} \mathrm{C}$ & $1^{\circ} \mathrm{C}$ & $\pm 5.0 \%$ of $\mathrm{rdg} \pm 4$ digits \\
\hline & & $0^{\circ} \mathrm{C}$ to $400{ }^{\circ} \mathrm{C}$ & $1^{\circ} \mathrm{C}$ & $\pm 1.0 \%$ of $\mathrm{rdg} \pm 3$ digits \\
\hline & & $400^{\circ} \mathrm{C}$ to $1000^{\circ} \mathrm{C}$ & $1^{\circ} \mathrm{C}$ & $\pm 2.0 \%$ of $\mathrm{rdg}$ \\
\hline C.A 1226 & Air velocity & $0.15-3 \mathrm{~m} / \mathrm{s}$ & $0.01 \mathrm{~m} / \mathrm{s}$ & $\pm 3 \% R+0.1 \mathrm{~m} / \mathrm{s}$ \\
\hline \multirow[t]{3}{*}{ thermoanemometer } & & $3.1-30 \mathrm{~m} / \mathrm{s}$ & $0.1 \mathrm{~m} / \mathrm{s}$ & $\pm 1 \% R+0.2 \mathrm{~m} / \mathrm{s}$ \\
\hline & Temperature & $-20^{\circ} \mathrm{C}$ to $+80^{\circ} \mathrm{C}$ & $0.1^{\circ} \mathrm{C}$ & $\pm 0.3 \% R+0.25^{\circ} \mathrm{C}$ \\
\hline & Air flow & $0-99999 \mathrm{~m}^{3} / \mathrm{h}$ & $1 \mathrm{~m}^{3} / \mathrm{h}$ & $\pm 3 \% R \pm 0.03$ surf. \\
\hline Light meter IM 1308 & Light meter & $40.0 \mathrm{~lx}-300.0 \mathrm{klx}$ & $\pm 3 \%$ & $\pm 5 \%$ reading $\pm 0.5 \%$ scale \\
\hline
\end{tabular}

Table 2

Periods of study.

\begin{tabular}{|c|c|c|c|c|c|c|}
\hline \multirow[t]{2}{*}{ Cities } & \multicolumn{3}{|l|}{ Dry season } & \multicolumn{3}{|l|}{ Rainy season } \\
\hline & Time & Months & Years & Time & Months & Year \\
\hline Douala & Four weeks & Nov.-May & 2011-2012 & Three weeks & Jul.-Aug. & 2012 \\
\hline Yaounde & Five weeks & Nov.-Feb. & 2011-2012 & Three weeks & May-Sep. & 2012 \\
\hline
\end{tabular}

used to calculate the PMV and PPD indices, in accordance with Fanger' model.

In most cases, thermal uniformity was difficult to achieve in classrooms and buildings. Hence, in this study, the measurement of the environmental parameters was conducted at various points occupied by the occupants who would be responding to the questionnaires.

\subsubsection{Subjective measurements}

The questionnaires employed in this work were distributed twice a day (before and after noon). This implied that 1450 questionnaires were collected and analysed during the study.

These questionnaires were constructed in accordance with the ISO 7730 [25] and ISO 10551 standards, as explained prior [26,27]. From these questionnaires, the clothing and metabolic rate were assessed as well as, it was also possible to know the sex, age, weight and size of each occupant. Finally, as in the previous research works, the questionnaires enabled the identification of the thermal sensation, thermal preference and acceptance of the thermal control of air movement and humidity in the areas occupied.

\section{Results and discussions}

Table 3 lists some results of the physical measurements obtained in 28 buildings and classes studied, located in two provinces situated in the central and coastal regions, as mentioned earlier. Overall, 63.2\% of the individuals in these areas of experience agreed to conduct this study with the subjects having an average age of 20.6 years in the classrooms and 28.0 years in the buildings.

\subsection{Thermal adaptation of the occupants}

The study of the thermal insulation and metabolic rate of occupants analysed in this work will be described in this section. In particular, it must be remembered that each occupant had adjusted their manner of clothing in accordance with their thermal sensation towards neutrality.

\subsubsection{Clothing value}

Fig. $2 \mathrm{a}$ and $\mathrm{b}$ indicate the thermal insulation versus the mean indoor operative temperature in Douala and Yaoundé. Insulation due to clothing is always the most difficult factor to be estimated in any field of investigation, due to the wide variety of clothing models and, consequently, this cannot be accurately estimated, in accordance with the clothing index tabulated by the ASHRAE and ISO standards. However, clothing insulation was calculated using the standard tabulations as well as from the insulation values obtained from two models as seen in the following equations:

$I_{\mathrm{cl}}=-0.05 \times T_{\mathrm{op}}+2.212, \quad R=0.66$ in Yaoundé
$I_{\mathrm{cl}}=-0.0685 \times T_{\mathrm{op}}+2.576, \quad R=0.792$ in Douala

From these models, it appears that clothing insulation changes inversely with the operative temperature (see, Fig. 2a and b). This resistance is strongly dependent upon the zone studied and the
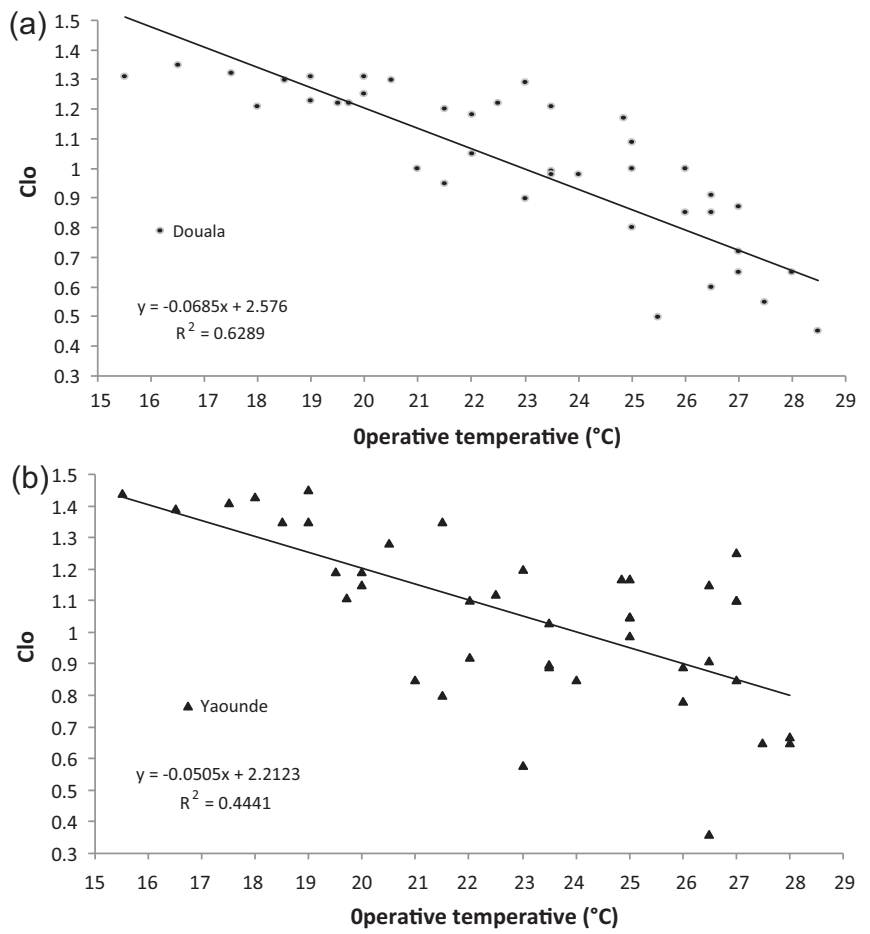

Fig. 2. (a) Thermal insulation versus mean indoor operative temperature in Douala (b). Thermal insulation versus mean indoor operative temperature in Yaoundé. 
Table 3

Physical measured data.

\begin{tabular}{|c|c|c|c|c|c|}
\hline Buildings \& classrooms & Operative temperature $\left({ }^{\circ} \mathrm{C}\right)$ & Mean velocity (m/s) & Mean $\mathrm{CO}_{2}$ rate (ppm) & Mean relative humidity (\%) & Mean luminosity (Lx) \\
\hline $\mathrm{C}_{1}$ & 26.5 & 0.23 & 980.5 & 67.5 & 157.5 \\
\hline $\mathrm{C}_{2}$ & 25.0 & 0.18 & 805.7 & 62.5 & 322.5 \\
\hline $\mathrm{C}_{3}$ & 26.3 & 0.11 & 530.5 & 68.7 & 246.0 \\
\hline $\mathrm{B}_{1}$ & 258 & 0.15 & 979.5 & 66.5 & 146.5 \\
\hline $\mathrm{B}_{2}$ & 23.5 & 0.06 & 923.5 & 70.6 & 178.5 \\
\hline $\mathrm{B}_{3}$ & 23.8 & 0.09 & 877.5 & 69.5 & 185.5 \\
\hline $\mathrm{B}_{4}$ & 22.7 & 0.07 & 818.4 & 71.5 & 201.5 \\
\hline $\mathrm{B}_{5}$ & 26.1 & 0.12 & 457.5 & 65.5 & 196.5 \\
\hline $\mathrm{B}_{6}$ & 24.9 & 0.17 & 558.3 & 67.8 & 211.5 \\
\hline $\mathrm{B}_{7}$ & 25.3 & 0.14 & 1061.5 & 70.9 & 117.5 \\
\hline $\mathrm{B}_{8}$ & 25.5 & 0.18 & 750.9 & 71.0 & 199.7 \\
\hline $\mathrm{B}_{9}$ & 24.8 & 0.13 & 558.5 & 68.5 & 110.9 \\
\hline $\mathrm{B}_{10}$ & 25.6 & 0.15 & 597.0 & 71.3 & 172.6 \\
\hline $\mathrm{B}_{11}$ & 26.1 & 0.17 & 858.5 & 68.5 & 100.4 \\
\hline $\mathrm{B}_{12}$ & 23.6 & 0.21 & 938.5 & 725 & 209.0 \\
\hline$B_{13}$ & 25.5 & 0.08 & 887.5 & 71.5 & 193.5 \\
\hline $\mathrm{B}_{14}$ & 25.9 & 0.29 & 1097.5 & 69.0 & 277.5 \\
\hline $\mathrm{B}_{15}$ & 24.8 & 0.10 & 920.0 & 72.7 & 205.6 \\
\hline $\mathrm{B}_{16}$ & 27.5 & 0.18 & 1011.0 & 69.0 & 230.5 \\
\hline $\mathrm{B}_{17}$ & 27.1 & 0.10 & 654.0 & 71.5 & 198.5 \\
\hline $\mathrm{B}_{18}$ & 26.3 & 0.21 & 967.5 & 71.5 & 254.5 \\
\hline $\mathrm{B}_{19}$ & 25.8 & 0.06 & 699.5 & 68.5 & 213.5 \\
\hline$B_{20}$ & 27.8 & 0.27 & 887.5 & 72.5 & 301.5 \\
\hline$B_{21}$ & 26.5 & 0.25 & 777.5 & 65.7 & 130.5 \\
\hline $\mathrm{B}_{22}$ & 24.9 & 0.30 & 1117.5 & 72.9 & 198.5 \\
\hline $\mathrm{B}_{23}$ & 27.6 & 0.12 & 548.5 & 59.5 & 205.7 \\
\hline $\mathrm{C}_{4}$ & 28.1 & 0.17 & 1039.0 & 67.5 & 159.9 \\
\hline$C_{5}$ & 25.8 & 0.27 & 626.0 & 68.9 & 135.9 \\
\hline
\end{tabular}

climate type. In particular, the range varies from 0.36 to $1.45 \mathrm{clo}$, with an average of 0.78 clo for Yaoundé, and between 0.45 and 1.37 clo with an average of 0.67 clo for Douala.

From these results, we can deduce that the resistance from clothing is much greater in the tropical wet cold (Yaoundé) than in the hot humid tropical climate (Douala). Once again, these results confirm the work of Moujalled Andal et al. [28] regarding the thermal insulation of clothing, for an average clo value of $0.3-0.7 \mathrm{clo}$. At the same time, Djongyang and Tchinda [16] found that with wearing tropical warm clothes, the clothing insulation ranged from 0.81 to 0.94 clo, thus enabling them to conclude that clothing insulation is highly dependent on the season. Therefore, during the dry season, thermal insulation, especially for men, ranged between 0.4 clo and 0.96 clo in both cities.

\subsubsection{Metabolic rate}

Metabolic rate was calculated from the descriptions of the activities of the individuals recorded in the various questionnaires, according to ISO 7730 [25]. The results obtained from this study, shows that in both Douala and Yaoundé the activities are subject to seasonal variations, being more intense in the dry than in the rainy season. Furthermore, for temperatures between $18.7^{\circ} \mathrm{C}$ and $28.5^{\circ} \mathrm{C}$, the average activity of 1.1 puts the hot humid tropics (Douala) against that of 1.05 in the cold tropics (Yaoundé). This result confirms that human activity slightly decreases with an increasing air temperature.

\subsection{Thermal sensation indices}

Thermal sensation ( $\left.T_{\text {sens }}\right)$ was obtained from the questionnaires and the different values thus obtained enabled us to arrive at Fig. 3, and several linear correlations, as evident from Eqs. (6) and (7). Several good correlations $\left(R^{2}=0.822\right.$ and $\left.R^{2}=0.937\right)$ between $T_{\text {sens }}$ and indoor air temperature are noted.

$T_{\text {sens }}=0.355 \times T_{\mathrm{a}}-8.843, \quad R_{2}=0.822$ in Douala

$T_{\text {sens }}=0.407 \times T_{\mathrm{a}}-9.855, \quad R_{2}=0.937$ in Yaoundé
The different $T_{\text {sens }}$ values obtained vary from -2.03 to 2.05 , with the average internal temperatures ranging from $16.5^{\circ} \mathrm{C}$ to $28.5^{\circ} \mathrm{C}$ in the tropical wet warm climate of Douala, and from -2.53 to 1.98 for a range of average internal temperatures between $18.8^{\circ} \mathrm{C}$ and $28.0^{\circ} \mathrm{C}$ in the tropical wet cold climate of Yaoundé. For $T_{\text {sens }}=0$ the average temperature of neutrality in Douala obtained during the two seasons was $25.0^{\circ} \mathrm{C}$, whereas in Yaoundé it was about $24.7^{\circ} \mathrm{C}$. Also, it was difficult to clearly recognise the rainy season in Yaoundé.
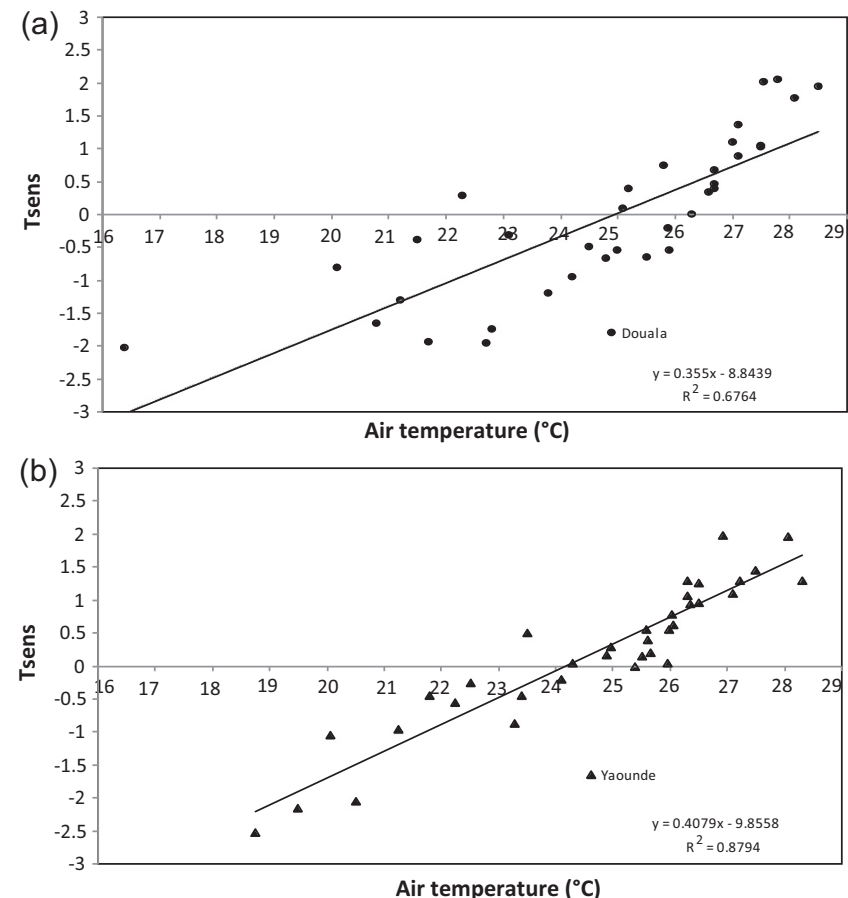

Fig. 3. (a) Thermal sensation versus indoor air temperature in Douala. (b). Thermal sensation versus indoor air temperature in Yaoundé. 
In Douala, the rainy season is characterised by flooding in several quarters. The average temperature hovers around $26.5^{\circ} \mathrm{C}$, except for October 5, when the minimum temperature recorded dropped below $17.0^{\circ} \mathrm{C}$. By contrast, Douala and Yaoundé have the common factor of a uniform temperature $\left(19.5^{\circ} \mathrm{C}\right)$, which corresponds to $T_{\text {sens }}=-1.93$, between late September and early October.

\subsection{Thermal acceptability, comfort and preferences}

\subsubsection{Thermal acceptability}

The acceptability and each thermal response to each different type of ambience was based on the PMV scale: -3 (cold), -2 (cool), -1 (slightly cool), 0 (Neutral), +1 (slightly warm), +2 (hot) and 3 (too hot). As the questionnaires had been based on this scale, Fig. $4 \mathrm{a}$ and $b$ reveal the results recorded during the two study seasons. In Fig. 4a, the dry season is shown for subjects who voted for indices $(-1,1) ; 56.22 \%$ of voters were acceptable towards the middle range in Douala, as against $47.16 \%$ in Yaoundé. Overall, $76.56 \%$ of the voters in the hot humid tropics (Douala) were acceptable as against $88.67 \%$ in the cold humid tropics (Yaoundé). these results obtained are near of the conclusions of Ibrahim Hussein during his field study in Malaysia [20] Moreover, only $12.98 \%$ of those indices $(-3,-2)$ and $(+2,+3)$ in Douala were not acceptable towards the medium range, as against $6.63 \%$ in Yaoundé. During the heavy rainy season (Fig. 4b), 76.52\% of the voter subjects appeared amenable towards the middle range in Yaoundé, as against $77.00 \%$ in Douala.

At the same time, the local thermal comfort can be analysed. Over the last few years several empirical equations used by some authors, like Simonson [30], have been available to do an indoor air quality study. Indices, such as the percentage of dissatisfaction with the local thermal comfort, thermal sensation and indoor air acceptability were determined in terms of some simple parameters like dry bulb temperature and relative humidity. Thus, the standard agreed upon by ANSI/ASHRAE and ISO 7730 to establish comfort boundary conditions was about $10 \%$ of dissatisfaction.

To meet the standards of local thermal comfort produced by the inside air conditions, Toftum et al. [31,32] studied the response of 38 individuals who were provided with clean air in a closed environment. As a result, the equation for the percentage of local dissatisfaction was developed as shown in the following equation:

$\mathrm{PD}=\frac{100}{1+e^{(-3.58+0.18 \times(30-t)+0.14 \times(42.5-0.01 \mathrm{Pv})}}$

ASHRAE recommends maintaining the percentage of local dissatisfaction below $15 \%$ and the percentage of general thermal
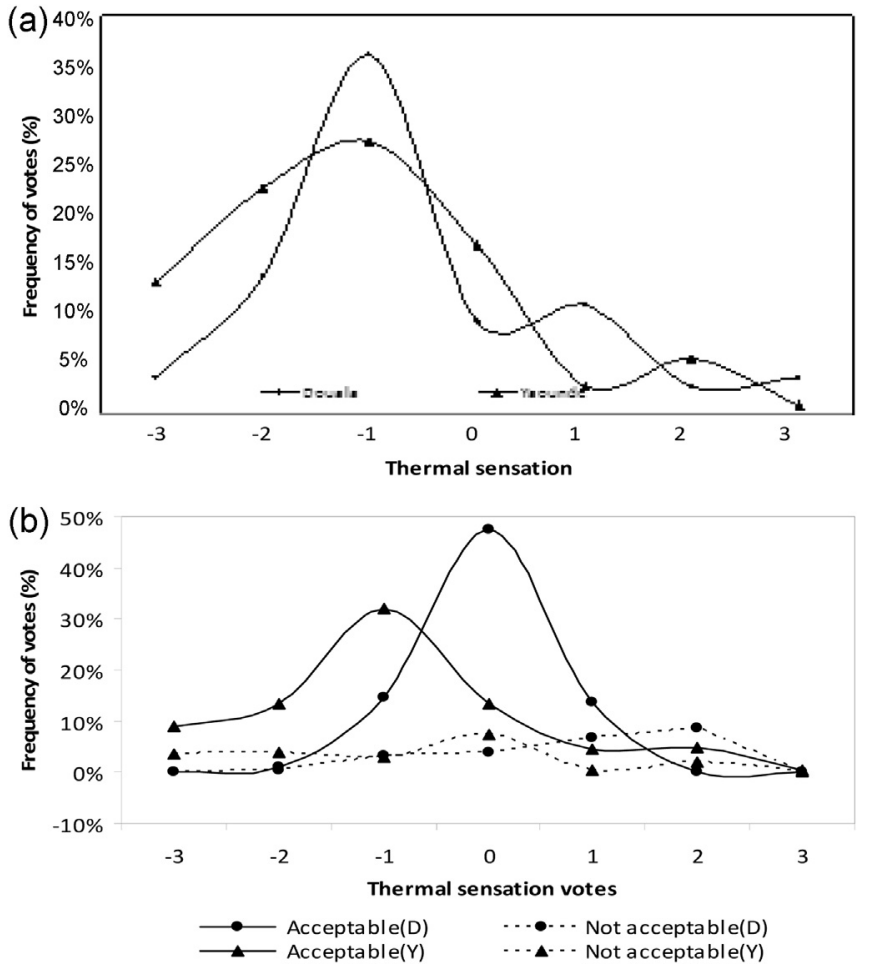

Fig. 4. (a) Thermal sensation during the dry season (b). Thermal sensation during the rainy season.

comfort dissatisfaction below $10 \%$. As seen, this PD tends to decrease when the temperature decreases and, consequently, these limiting conditions can be employed to define the optimal conditions for energy saving in the air conditioning systems. Consequently, Fig. 5 shows the indoor local thermal comfort conditions in keeping with the previous indices. When the indoor air temperature varied between $26.5^{\circ} \mathrm{C}$ and $28.0^{\circ} \mathrm{C}$, the $\mathrm{PD} \geq 50 \%$. This result shows that the percentage of general thermal comfort dissatisfaction evolved in the same way as air temperature.

\subsubsection{Thermal comfort}

In Fig. 6a, an average $76.10 \%$ of the voters opted for a comfortable environment, with $71.10 \%$ for the city of Douala against $81 \%$ in Yaoundé during the dry season. Thermal sensations vary between individuals in the same environment and in different

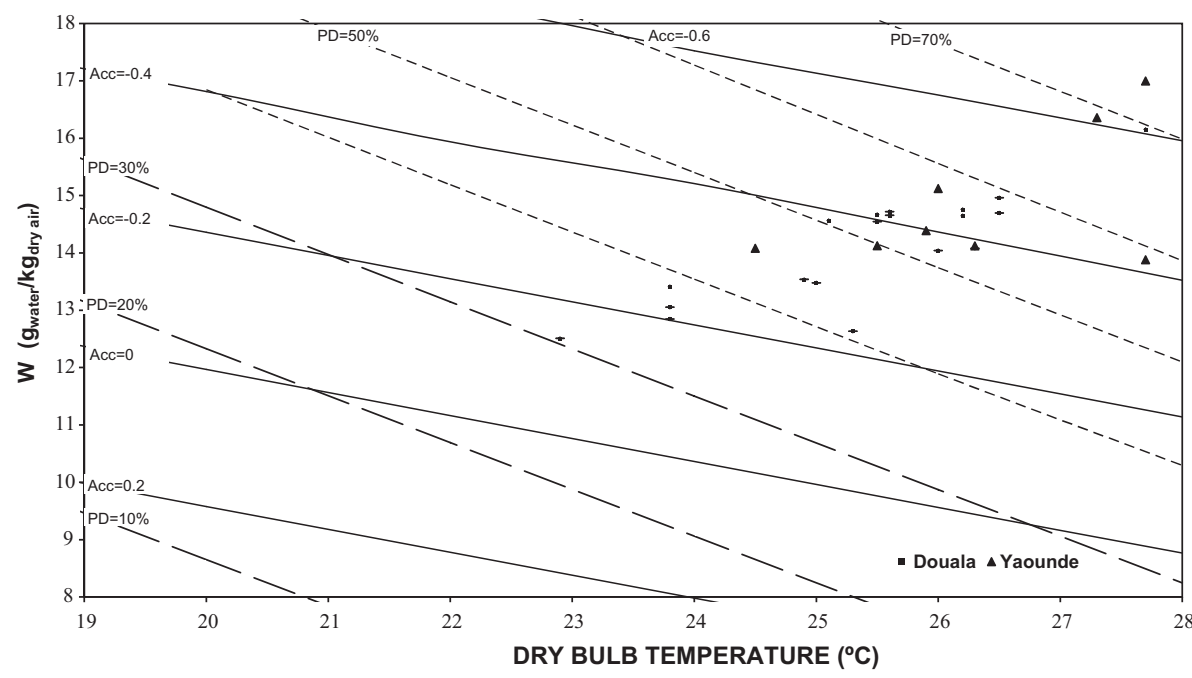

Fig. 5. Local thermal comfort conditions. 

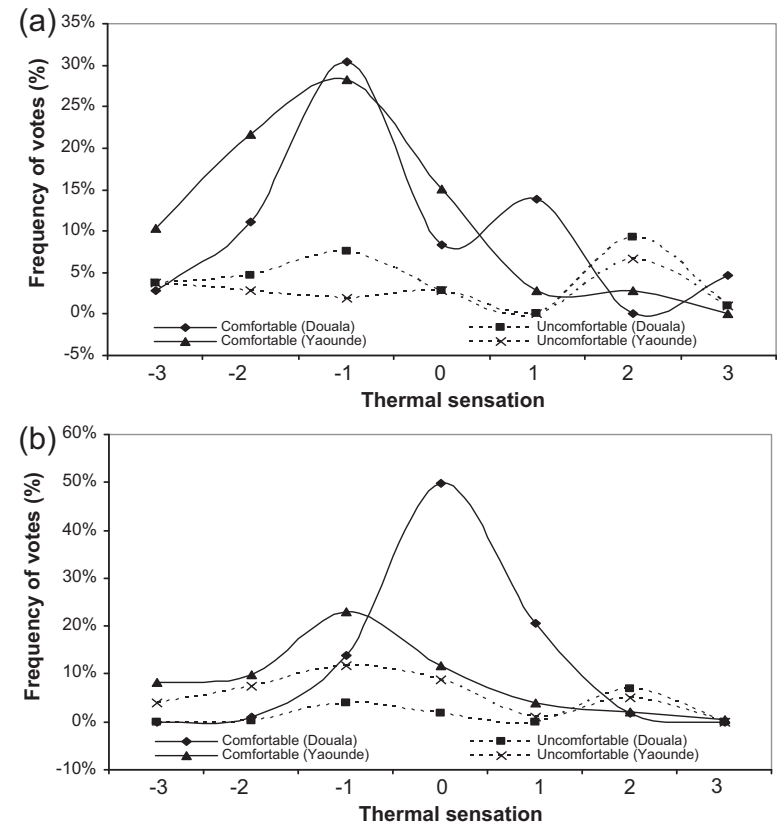

Fig. 6. (a) Thermal comfort during the dry season. (b) Thermal comfort during the rainy season.

regions $[15,16]$. Of the $38 \%$ of the subjects with voting indices of $(-3,-2)$, and $(+2,+3), 19 \%$ found a comfortable environment for Douala, unlike for Yaoundé or in other words 35\% of 50\% found the place comfortable. In Fig. $6 \mathrm{~b}$, it appears that $87.0 \%$ of the voters in Douala found a comfortable environment during the rainy season, as against 59.4\% in Yaoundé. In general, during the 23-month study, $79.5 \%$ of the subjects participated in the voting, as against $70.1 \%$ in Douala compared with Yaoundé, who found a comfortable environment. A total of $31.5 \%$ of the voters in Douala, against $19.5 \%$ of those who voted in Yaoundé, found their neutral environment. We deduce from these results, that a medium neutral does not necessarily indicate a comfortable environment [16-18].

\subsubsection{Thermal preference}

Thermal preferences and thermal sensations depend on the physical, psychological and physiological factors, which are unpredictable. Fig. 7a shows the results obtained by the different thermal preferences during the dry season. Fig. 7a indicates that, in Douala, $74.5 \%$ of the voters desire an unchanged environment, against $59.49 \%$ for Yaoundé. Also, $19.84 \%$ of the occupants wish for a cooler environment in Yaoundé, as against 25.97\% in Douala. For this factor, for the rainy season, the data from Fig. $7 \mathrm{~b}$ shows that $31.35 \%$ of the voters wish for a warmer environment in Yaoundé, as against $13.01 \%$ in Douala. Overall, during the entire experimental period, in the dry and rainy seasons, more occupants desired their environment to remain unchanged. An analysis of these different results show that thermal sensation and thermal preference varied according to type of building and also according to season. This conclusion confirm the results found in the last works [34-36].

\subsection{Internal environmental parameters}

Fig. 8 reveals the evolution of the average internal temperature and relative humidity. In Douala, the average temperature varies from $24.5^{\circ} \mathrm{C}$ to $28.8^{\circ} \mathrm{C}$, while the relative humidity values range from $49.9 \%$ to $73.4 \%$. In Yaoundé, humidity ranges from $46.8 \%$ to $73.7 \%$, while the average temperature varies from between $23.3^{\circ} \mathrm{C}$ and $26.8^{\circ} \mathrm{C}$. In most cases, the relative humidity values obtained
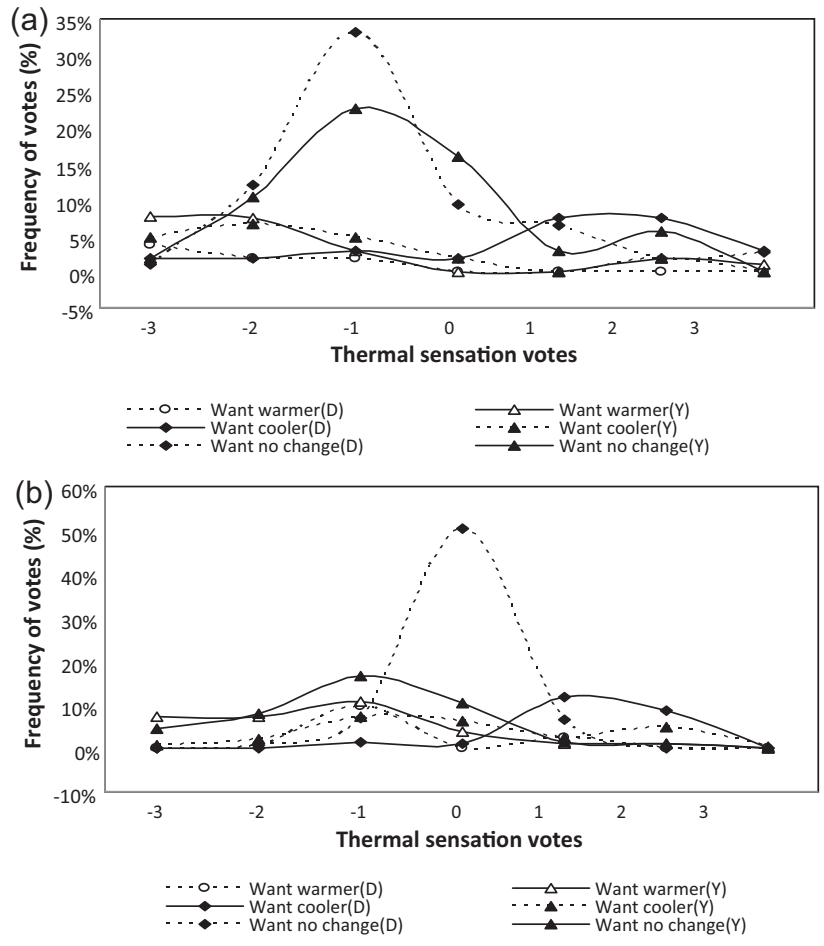

Fig. 7. (a) Votes of thermal preference during the dry season (b). Votes of thermal preference during the rainy season.

were not in accordance with the ASHRAE comfort range established between $30 \%$ and $60 \%$ by CIBSE $[2,3]$.

In Fig. 9a, the average wind speed is $0.085 \mathrm{~m} / \mathrm{s}$, alternating between $0.01 \mathrm{~m} / \mathrm{s}$ and $0.31 \mathrm{~m} / \mathrm{s}$ in Yaoundé, as against $0.05 \mathrm{~m} / \mathrm{s}$ and $0.32 \mathrm{~m} / \mathrm{s}$ in Douala. Other parameters like $\mathrm{CO}_{2}$ concentration and luminosity also exert their influence on the indoor comfort of a building. In Fig. 9b, indoor $\mathrm{CO}_{2}$ concentration differs depending on the building materials that had been used, relevant to the habitat and time. The $\mathrm{CO}_{2}$ concentration varies from $533 \mathrm{ppm}$ to 1168 ppm, with the recorded average being 832.5 ppm in Douala, as against $887.5 \mathrm{ppm}$ in Yaoundé. Elevated $\mathrm{CO}_{2}$ rate in a building affect the health of occupant [33]. In fact, a high level of $\mathrm{CO}_{2}$ can cause headache and changes in breath rhythms in houses [33]. The effect of luminosity has not always been good in the offices studied. Luminosity varied from 100.4 to $322.5 \mathrm{~lx}$, when it is inferior to $200 \mathrm{~lx}$ in an office, it influences on the health (see Table 3).

Different outdoor parameters (air temperature, relative humidity and wind speed) also influence indoor comfort. These elements have been studied and are discussed in the next paragraph.

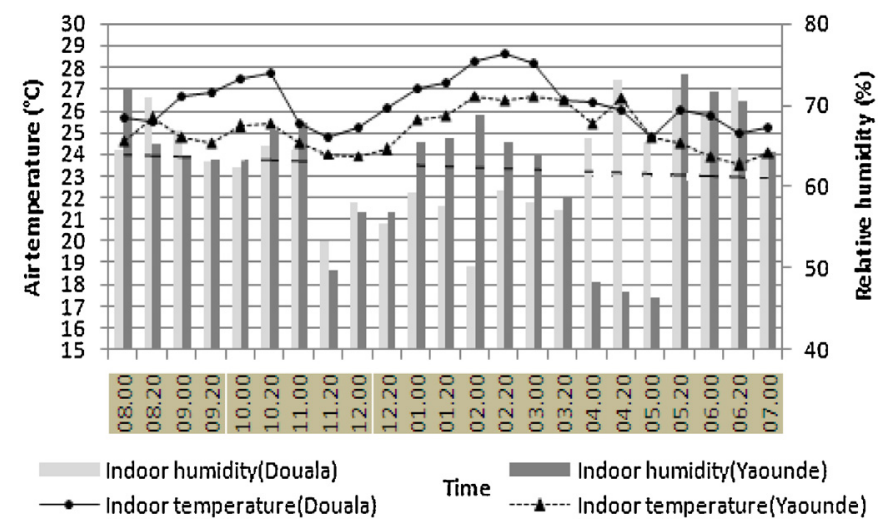

Fig. 8. Temperature and relative humidity in the two cities. 

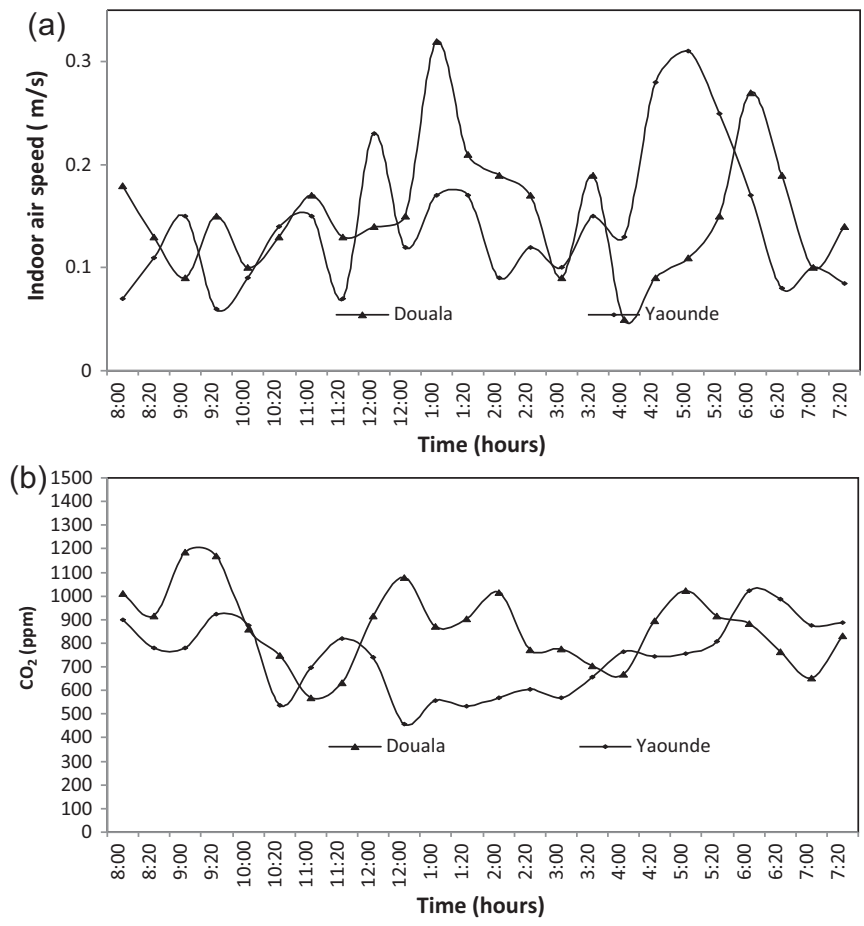

Fig. 9. (a) Air speed for the two cities. (b) Indoor $\mathrm{CO}_{2}$ concentration for the two cities.

\subsection{Outdoor air}

The relative humidity, as well as wind speed and air temperature, exerts a great influence on the thermal sensations and preferences within a building. In Fig. 10, the monthly averages of different outdoor temperatures have been recorded for the month of October 2010 leading up to September 2012. In Douala city, the temperatures are above $26.0^{\circ} \mathrm{C}$, except for the month of August 2011 , where it is $25.6^{\circ} \mathrm{C}$. Moreover, in Yaoundé, the external temperature varies from $23.3^{\circ} \mathrm{C}$ (corresponding to October 2010) to $25.9{ }^{\circ} \mathrm{C}$ (November 2011). Relative humidity is not predictable because it is nonlinear. By analysing the relative humidity values of the data recorded for 24 successive months in Fig. 11, we observe that it varies from $77.0 \%$ to $90.0 \%$ for Douala with an average value of $86 \%$, while in Yaoundé, the values range between $71.0 \%$ and $85.0 \%$, and average at $73.7 \%$. We conclude that the relative humidity is much greater in Douala than in Yaoundé. The location of Douala is certainly one of the main causes for this increase in the relative humidity in the humid warm tropics. From August 2011 to February 2012, the humidity decreased considerably in both the cities.

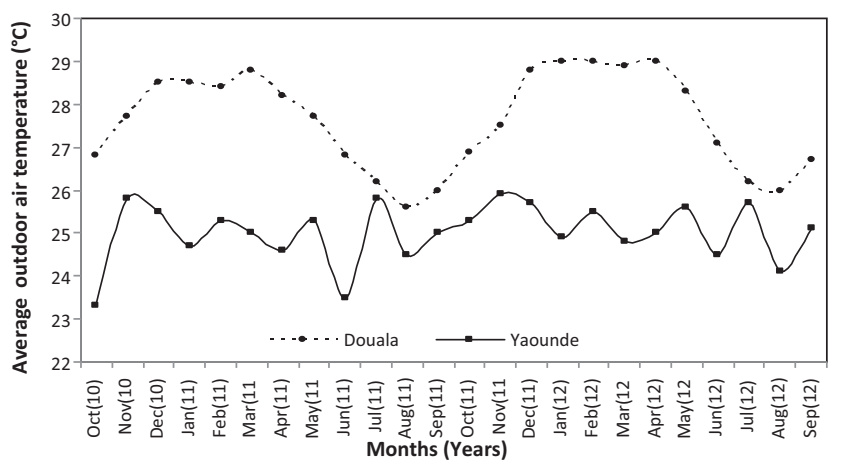

Fig. 10. Outdoor average air temperature for the two cities.

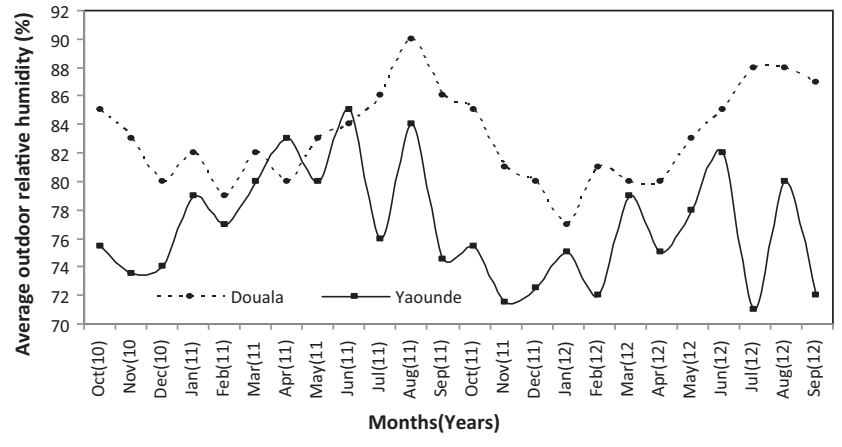

Fig. 11. Outdoor average relative humidity for the two cities.

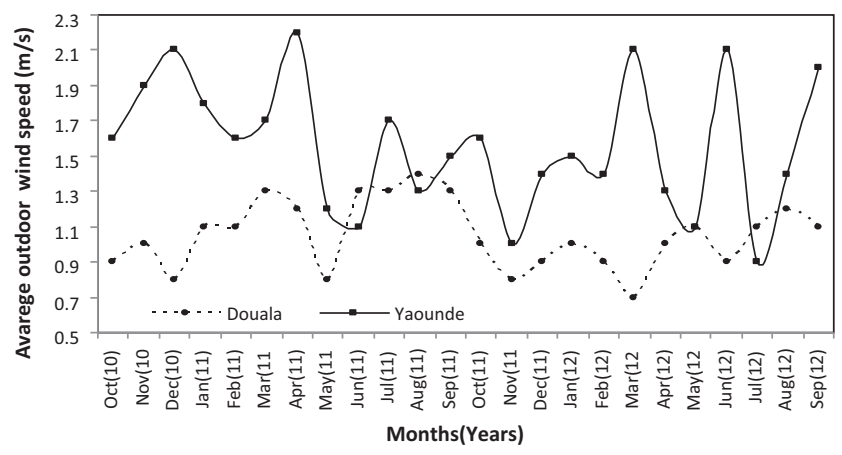

Fig. 12. Outdoor average wind speed for the two cities.

While the wind speed is higher in Yaounde than in Douala, according to the different values obtained in accordance with Fig. 12 , the wind speed varies from $0.9 \mathrm{~m} / \mathrm{s}$ to $2.2 \mathrm{~m} / \mathrm{s}$ and $0.7 \mathrm{~m} / \mathrm{s}$ to $1.4 \mathrm{~m} / \mathrm{s}$, respectively, for the cities of Yaoundé and Douala. The average is $1.4 \mathrm{~m} / \mathrm{s}$, an average of $1.0 \mathrm{~m} / \mathrm{s}$ in Douala, as against the $1.8 \mathrm{~m} / \mathrm{s}$ in Yaoundé. The location of Yaoundé, a city considered to be built on seven hills, certainly influences the wind speed velocity in this region.

The results obtained emphasise the importance of thermal comfort in the areas of study and work (offices). Preferences and thermal sensations vary according to the individual, even if they come from the same area and are subject to the same type of climate [37]. The buildings constructed with local materials, recent as well as those over 25 years of age, are less informed, and less than polluting establishments and newly built offices. The rate of the average $\mathrm{CO}_{2}$ concentration is much higher in Yaoundé than in Douala. The acceptable temperature ranges from $22.4^{\circ} \mathrm{C}$ to $26.7^{\circ} \mathrm{C}$ in Yaoundé, and from $24.3^{\circ} \mathrm{C}$ to $27.8^{\circ} \mathrm{C}$ in Douala.

\section{Conclusion}

In this work, an investigation into the experimental and subjective results of thermo-hygrometrical comfort conducted in 28 buildings and schools located in two cities of the wet tropical climatic zone of Cameroon is presented. A total of 1450 questionnaires were used for both the dry and rainy seasons, while different experimental values of indoor parameters were measured. Also, external environmental parameters, such as the average monthly outside temperature, wind speed and relative humidity in the two cities, were reported. The conclusions drawn from this study are as follows:

- Individuals express their feelings and thermal preferences differently.

- The average thermal insulation is 0.78 clo in Yaoundé, as against 0.67 clo in Douala. 
- For $T_{\text {sens }}=0$, the average temperature of neutrality obtained in Douala during the two seasons is $25.0^{\circ} \mathrm{C}$ and $24.7^{\circ} \mathrm{C}$ in Yaoundé.

- Newly built habitats are more polluting.

- $76.7 \%$ of the voters in Douala are environmentally oriented, as against $82.6 \%$ in Yaoundé.

- In Douala and Yaoundé, during the different seasons, voters desire their environments to remain unchanged.

- In both cities, the results of the analysis of the physical measurements are different from those given by the voters. Constructions are haphazard and do not take into account the majoritylanguage cases, separating them into an account-planning aspect of microclimate. Local materials are used in favour of imported materials. Before beginning a construction, it is advisable to conduct a preliminary study on the type of climate prevailing in the region to adapt to the type of the corresponding construction material. The choice of ventilation and air conditioning systems, humidifiers and fans, is highly important as they are the ones that pollute and consume less electricity. The choice of materials, depending on the climatic constraints, can be a solution to overcome the uncomfortable heat.

\section{Acknowledgements}

The authors are grateful to the various authorities of the two cities selected for the research who provided the opportunity to examine and study the information relevant to their localities. The authors also thank the head of the National Weather Station and all those, near and far, who participated in the preparation of this work during the period of the field study.

\section{References}

[1] R. De Dear, G. Brager, D. Cooper, Developing an adaptive model of thermal comfort and preference, in: Final Report-ASHRAE Project RP 884, 1997.

[2] ASHRAE, Thermal environmental conditions for human occupancy, in: ASHRAE Standard 55, ASHRAE, Atlanta, 2004.

[3] CIBSE, CIBSE Guide A, The Chartered Institution of Building Services Engineers, Yale Press, London, 1999.

[4] Y.H. Yau, A preliminary thermal comfort study in tropical buildings located in Malaysia, International Journal of Mechanics and Materials in Design 3 (2) (2008) 119-126.

[5] K. Qi Jie, N.M. Adam, Thermal comfort in enclosed lift lobby of a tropical educational institution, International Journal of Advanced Science and Technology 15 (3) (2010) 8-18.

[6] G. Zhang Andal, Thermal comfort investigation of naturally ventilated classrooms in a subtropical region, Building and Environment 16 (2007) 148-158.

[7] R. Daghigh, K. Sopian, Effective ventilation parameters and thermal comfort study of air-conditioned offices, American Journal of Applied Sciences 6 (5) (2009) 943-951.

[8] P.O. Fanger, Comfort Thermique, MC Graw Hill, New York, NY, 1970

[9] Z. Lin, S. Deng, A study on the thermal comfort in sleeping environments in the subtropics-developing a thermal comfort model for sleeping environments, Building and Environment 43 (2008) 70-80.

[10] J.F. Nicol, M.A. Humphreys, Adaptive thermal comfort and sustainable thermal standards for buildings, Energy and Buildings 34 (2002) 563-572.

[11] N.H. Wong, S.S. Khoo, Thermal comfort in classrooms in the tropics, Energy and Buildings 35 (2003) 337-351.
[12] F. Henry, N.H. Wong, Thermal comfort for naturally ventilated houses in Indonesia, Energy and Buildings 36 (7) (2004) 614-626.

[13] S. Paolo Corgnati, Roberta Ansaldi, Marco Filippi, Thermal comfort in Italian classrooms under free running conditions during the mid-seasons: assessment through objective and subjective approaches, Building and Environment 44 (2009) 785-792.

[14] A. Wagner, L. Roberto, Thermal comfort in buildings located in regions of hot and humid climate of Brazil, Energy and Buildings 1 (23) (2005) 1-22.

[15] L. Zambrano, C. Malafaia, L.E.G. Bastos, Thermal comfort evaluation in outdoor space of tropical humid climate, in: PLEA 2006-The 23rd Conference on Passive and Low Energy Architecture, Geneva, Switzerland 6-8 September, 2006.

[16] N. Djongyang, R. Tchinda, Estimation of some comfort parameters for sleeping environments in the dry-tropical sub-Saharan Africa region, Energy Conversion and Management 58 (2012) 110-119.

[17] A.G. Kwok, Thermal comfort in tropical classrooms, ASHRAE Transactions 104 (1B) (1998) 1031-1047.

[18] N.H. Wong, K.W. Cheong, Thermal comfort evaluation of naturally ventilated public housing in Singapore, Building and Environment 37 (2002) 1267-1277.

[19] H. Feriadi, N.H. Wong, Thermal comfort for naturally ventilated houses in Indonesia, Energy and Buildings 36 (2004) 614-626.

[20] I. Hussein, M.H.A. Rahman, Field study on thermal comfort in Malaysia, European Journal of Scientific Research 37 (1) (2009) 134,52.

[21] H. Hens, Thermal comfort in office buildings: two case studies commented Building and Environment 44 (2009) 1399-1408.

[22] A.C. Ogbonna, D.J. Harris, Thermal comfort in sub-Saharan Africa: field study report in Jos-Nigeria, Applied Energy 85 (2008) 1-11.

[23] B.W. Zingano, A discussion on thermal comfort with reference to bath water temperature to deduce a midpoint of the thermal comfort temperature zone, Renewable Energy 23 (2001) 7-41.

[24] M. Miyazawa, Seasonal changes of sleep environment at bedtime and on arising, in: The Proceeding of the 18th Symposium on Human-Environment System, 1994.

[25] I.S.O., Ergonomics of the thermal environment analytical determination and interpretation of thermal comfort using calculation of the PMV and PPD indices and local thermal comfort criteria, in: I.S.O. 7730 Standard, I.S.O., London, UK, 2005.

[26] UNI EN ISO, Ergonomia degli ambienti termici-valutazione dell'influenza dell'ambiente termico mediante scale di giudizio soggettivo, in: UNI EN ISO 10551, UNI EN ISO, Gennaio, 2002.

[27] A. Tuan Nguyen, M. Kumar Singh, S. Reiter, An adaptive thermal comfort model for hot humid south-east Asia, Building and Environment 56 (2012) 291-300.

[28] B. Moujalled Andal, Comparison of thermal comfort algorithms in naturally ventilated office buildings, Energy and Buildings 40 (2008) 2215-2223.

[29] K. Nagano, T. Mochida, Experiments on thermal design of ceiling radiant cooling for supine human subjects, Building and Environment 39 (2004) 267-275

[30] C.J. Simonson, M. Salonvaara, T. Ojanen, Improving Indoor Climate and Comfort with Wooden Structures, Technical Research Centre of Finland, Espoo, 2001.

[31] J. Toftum, A.S. Jorgensen, P.O. Fanger, Upper limits for indoor air humidity to avoid uncomfortably humid skin, Energy and Buildings 28 (1998) 1-13.

[32] J.Toftum, A.S. Jorgensen, P.O. Fanger, Upper limits of air humidity for preventing warm respiratory discomfort, Energy and Buildings 28 (1998) 15-23.

[33] M. Nematchoua, R. Tchinda, A. José, R. Gholamreza, Study of dioxide carbon concentration and indoor air quality in some buildings in the equatorial region of Cameroon (Yaounde), International Journal of Health Sciences 2 (2) (2014) $1-15$.

[34] P. Ricciardi, C. Buratti, Thermal comfort in open plan offices in northern Italy: an adaptive approach, Building and Environment 56 (2012) 314-3207.

[35] C. Buratti, P. Ricciardi, Adaptive analysis of thermal comfort in university classrooms: correlation between experimental data and mathematical models, Building and Environment 44 (2009) 674-687.

[36] A.S. Dili, M.A. Naseer, Z. Varghese, Thermal comfort study of Kerala traditional residential buildings based on questionnaire survey among occupants of traditional and modern buildings, Energy and Buildings 42 (2010) 2139-2150.

[37] M. Nematchoua, R. Tchinda, A. José, Thermal comfort and energy consumption in modern versus traditional buildings in Cameroon: a questionnaire-based statistical study, Applied Energy 114 (2014) 687-699. 